\title{
Prospective risk of unexplained stillbirth in singleton pregnancies at term: population based analysis
}

\author{
Christina S Cotzias, Sara Paterson-Brown, Nicholas M Fisk
}

Unexpected late fetal death is tragic but not uncommon, most such fetal deaths being unexplained. Although five times more common than sudden infant death, ${ }^{1}$ they have attracted scant public attention.

Delivery is recommended when the risks to the fetus in utero are greater than those to the baby after birth; in high risk pregnancies this is generally believed to be around 38 weeks. The risk of unexplained stillbirth near term is, however, relevant to all pregnancies. Current numerical estimates do not detail risk by gestation, ${ }^{1}$ and the few studies that have done so are no longer applicable in the United Kingdom in the late 1990s. Yudkin et al calculated the total risk of stillbirth by gestation using population data that are currently over 15 years old, ${ }^{2}$ while Feldman calculated a prospective risk using data from a New York City population, including multiple pregnancies and a high proportion of women with no antenatal care. ${ }^{3}$ We calculated prospective risks of unexplained stillbirth by gestation in singleton pregnancies near term.

\section{Methods and results}

We reviewed published data on 171527 births in the North East Thames region in $1989-91^{4}$ and derived the number of ongoing pregnancies and stillbirths at or beyond each gestational week from 35 to 43 weeks. The prospective stillbirth rate per 1000 ongoing pregnancies was calculated as the number of stillbirths at or beyond week $\mathrm{n}$ divided by the number of pregnancies at or beyond week $\mathrm{n}$ multiplied by 1000 , where $\mathrm{n}$ is the week of gestation from 35 to 43 weeks.

As the original dataset included all stillbirths (explained and unexplained and those in multiple pregnancies), we applied correction factors to derive gestation specific risks of unexplained stillbirth in singleton pregnancies near term as follows. We used data from the Office for National Statistics for 1994 to estimate the proportion of all births (live births and stillbirths) that were singleton (650 826/
$659545=0.9868)$ and the proportion of overall stillbirths that were in singleton pregnancies (3465/ $3813=0.9087)$. We used data from the 1994 confidential enquiry into stillbirths and deaths in infancy ${ }^{1}$ to estimate the proportion of total stillbirths of fetuses $>2500 \mathrm{~g}$ that were unexplained $(833 / 1137=0.7326)$.

The table shows the risk of stillbirth in ongoing pregnancies. At or beyond 38 weeks one in 730 singleton pregnancies were complicated by an unexplained stillbirth at term and one in 529 by stillbirth of any cause. Stillbirths of any cause may be more relevant because all stillbirths beyond 38 weeks are arguably unexpected since fetuses with recognised risk factors have usually been delivered by this time.

\section{Comment}

We acknowledge that the risks we report are approximations, being derived from three sources of data, but they provide the first quantifiable estimate of risk in continuing singleton pregnancies near term. This information is relevant to modern obstetric practice, where women want to be informed and have high expectations about the safety of their unborn child. Most women would want a caesarean section if the risk of fetal death or damage to their child exceeded one in $4000 .{ }^{5}$ Our calculations show that the risk of stillbirth at term is five to eight times higher than this.

Interestingly, at 38 weeks the risks of stillbirth near term exceed those at 42 weeks, when delivery is usually recommended. Delivering women routinely at 38 weeks would lead to a high incidence of caesarean section with its attendant risks, either primarily or from failed induction, in addition to a small risk of iatrogenic neonatal respiratory morbidity.

Antepartum stillbirth is a major public health problem, accounting for a greater contribution to perinatal mortality than either deaths as a consequence of prematurity or the sudden infant death syndrome. Research into the underlying mechanisms and

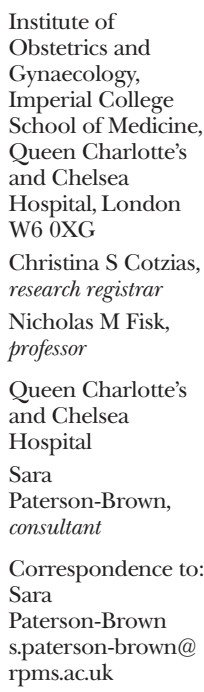

BMJ 1999;319:287-8

Unexplained stillbirths and total prospective risk of stillbirth by gestation

\begin{tabular}{|c|c|c|c|c|c|c|c|c|c|c|}
\hline $\begin{array}{l}\text { Gestation } \\
\text { (weeks) }\end{array}$ & $\begin{array}{c}\text { Total No of } \\
\text { ongoing } \\
\text { pregnancies }\end{array}$ & $\begin{array}{c}\text { No of singleton } \\
\text { ongoing } \\
\text { pregnancies }\end{array}$ & $\begin{array}{c}\text { No of } \\
\text { stillbirths } \\
\text { per week }\end{array}$ & $\begin{array}{l}\text { Total No of } \\
\text { stillbirths at } \\
\text { or beyond } \\
\text { each week }\end{array}$ & $\begin{array}{c}\text { No of } \\
\text { singleton } \\
\text { stillbirths at } \\
\text { or beyond } \\
\text { each week }\end{array}$ & $\begin{array}{l}\text { Total No of } \\
\text { stillbirths } \\
/ 1000 \text { ongoing } \\
\text { pregnancies }\end{array}$ & $\begin{array}{l}\text { Total No of } \\
\text { singleton } \\
\text { stillbirths/1000 } \\
\text { ongoing singleton } \\
\text { pregnancies } \\
(95 \% \mathrm{CI})\end{array}$ & $\begin{array}{c}\text { Prospective } \\
\text { risk of total } \\
\text { stillbirths in } \\
\text { singleton } \\
\text { pregnancies }\end{array}$ & $\begin{array}{l}\text { No of unexplained } \\
\text { singleton } \\
\text { stillbirths/1000 } \\
\text { ongoing } \\
\text { pregnancies } \\
(95 \% \mathrm{Cl})\end{array}$ & $\begin{array}{l}\text { Prospective } \\
\text { risk of } \\
\text { unexplained } \\
\text { stillbirth } \\
\text { antepartum in } \\
\text { singleton } \\
\text { pregnancies }\end{array}$ \\
\hline 35 & 164860 & 162684 & 54 & 489 & 444 & 2.97 & 2.73 (2.48 to 2.99$)$ & $1: 366$ & 2.00 (1.79 to 2.23$)$ & $1: 500$ \\
\hline 36 & 162603 & 160457 & 73 & 435 & 395 & 2.68 & 2.46 (2.22 to 2.72 ) & $1: 407$ & 1.80 (1.60 to 2.02 ) & $1: 556$ \\
\hline 37 & 158171 & 156083 & 56 & 362 & 329 & 2.29 & 2.11 (1.89 to 2.35) & $1: 474$ & 1.55 (1.36 to 1.76$)$ & $1: 645$ \\
\hline 38 & 149181 & 147212 & 83 & 306 & 278 & 2.05 & 1.89 (1.67 to 2.12) & $1: 529$ & 1.37 (1.20 to 1.58$)$ & $1: 730$ \\
\hline 39 & 127160 & 125481 & 72 & 223 & 203 & 1.75 & 1.62 (1.40 to 1.86$)$ & $1: 617$ & 1.19 (1.00 to 1.39$)$ & $1: 840$ \\
\hline 40 & 93828 & 92589 & 81 & 151 & 137 & 1.61 & 1.47 (1.24 to 1.75) & $1: 680$ & 1.08 (0.88 to 1.31$)$ & $1: 926$ \\
\hline 41 & 39316 & 38797 & 50 & 70 & 64 & 1.78 & 1.65 (1.27 to 2.11) & $1: 606$ & 1.21 (0.89 to 1.61$)$ & $1: 826$ \\
\hline 42 & 10328 & 10192 & 16 & 20 & 18 & 1.94 & 1.77 (1.05 to 2.79$)$ & $1: 565$ & 1.30 (0.68 to 2.18$)$ & $1: 769$ \\
\hline 43 & 1883 & 1858 & 4 & 4 & 4 & 2.12 & $2.15(0.59$ to 5.50$)$ & $1: 465$ & $1.58(0.33$ to 4.71$)$ & 1:633 \\
\hline
\end{tabular}


aetiological factors of this problem to identify pregnancies at risk must remain a prerequisite for any selective strategy to prevent these deaths.

Contributors: CSC refined the methodology, collected and analysed the data, and drafted the paper. SP-B contributed to the study design, analysis, and paper drafts. NMF had the original idea for the study and contributed to drafting and revising the paper. CSC is guarantor for the study.

Funding: None.

Competing interests: None declared.
1 Confidential Enquiry into Stillbirths and Deaths in Infancy. Fourth and fifth annual reports. London: Stationery Office, 1996 and 1998.

2 Yudkin PL, Wood L, Redman CWG. Risk of unexplained stillbirth at different gestational ages. Lancet 1987;i:1192-4

3 Feldman G. Prospective risk of stillbirth. Obstet Gynecol 1992;79:547-52.

4 Hilder L, Costeloe K, Thilaganathan B. Prolonged pregnancy: evaluating gestation-specific risks of fetal and infant mortality. Br J Obstet Gynaecol 1998;105:169-73.

5 Thornton J, Lilford R. The caesarean section decision: patients' choices are not determined by immediate emotional reactions. J Obstet Gynaecol $1989 \cdot 9 \cdot 283-8$

\section{Predicted impact of intravenous thrombolysis on prognosis of general population of stroke patients: simulation model}

Henrik Stig Jørgensen, Hirofumi Nakayama, Lars Peter Kammersgaard, Hans Otto Raaschou, Tom Skyhøj Olsen

Department of Neurology, Bispebjerg Hospital, Bispebjerg bakke 23, DK-2400 Copenhagen NV, Denmark

Henrik Stig Jørgensen consultant

Hirofumi

Nakayama

senior registrar

Lars Peter

Kammersgaard

senior registrar

Hans Otto

Raaschou

consultant

Department of

Neurology,

Gentofte Hospital,

Copenhagen,

Denmark

Tom Skyhøj Olsen associate professor

Correspondence to: H S Jørgensen hsj@dadlnct.dk

BMJ 1999;319:288-9
Alteplase (recombinant tissue plasminogen activator) can be used to dissolve blood clots and achieve reperfusion in some stroke patients. Three randomised controlled trials have studied its clinical effect. ${ }^{1-3}$ A US trial studied patients who were treated within three hours of onset of stroke and reported a 32\% (95\% confidence interval $1 \%$ to $70 \%$ ) relative increase in the proportion of patients with full recovery but no effect on overall mortality. ${ }^{1}$ This led to approval of alteplase for stroke patients in the United States. A European trial of patients treated within six hours of stroke onset was negative, ${ }^{2}$ and a second trial, published recently, reported no significant positive effect. ${ }^{3}$ An application for European approval of alteplase treatment within three hours of stroke onset is being considered. Alteplase often leads to bleeding and should be given only by specialised teams. ${ }^{3}$ Reorganisation of stroke treatment is therefore necessary if alteplase is approved. The trials were performed in highly selected patients. ${ }^{1-3}$ To elucidate the effect of alteplase on the general stroke population we conducted a retrospective analysis, applying the exclusion criteria and treatment effect reported in the US trial ${ }^{1}$ to the unselected stroke population of the Copenhagen stroke study (COST). ${ }^{4}$

\section{Subjects, methods, and results}

COST comprised 1197 patients with acute stroke recruited during 1991-3 from an area of Copenhagen. ${ }^{4}$ These patients constituted $88 \%$ of stroke patients in the area: the remaining 12\% were not admitted because they had very mild stroke or died before reaching hospital; none would have qualified for alteplase treatment. The figure shows the impact of each exclusion criterion from the US trial ${ }^{1}$ on the COST population. Only $64(5 \%)$ of the patients fulfilled all criteria. Nineteen of these patients died, and 17 had full recovery (defined as 95 or 100 points on the Barthel index at discharge ${ }^{1}$ ). These patients would therefore not have benefited from alteplase treatment. The 28 patients who survived but did not achieve full recovery could have benefited from treatment. With a $32 \%$ relative increase in patients with full recovery, five

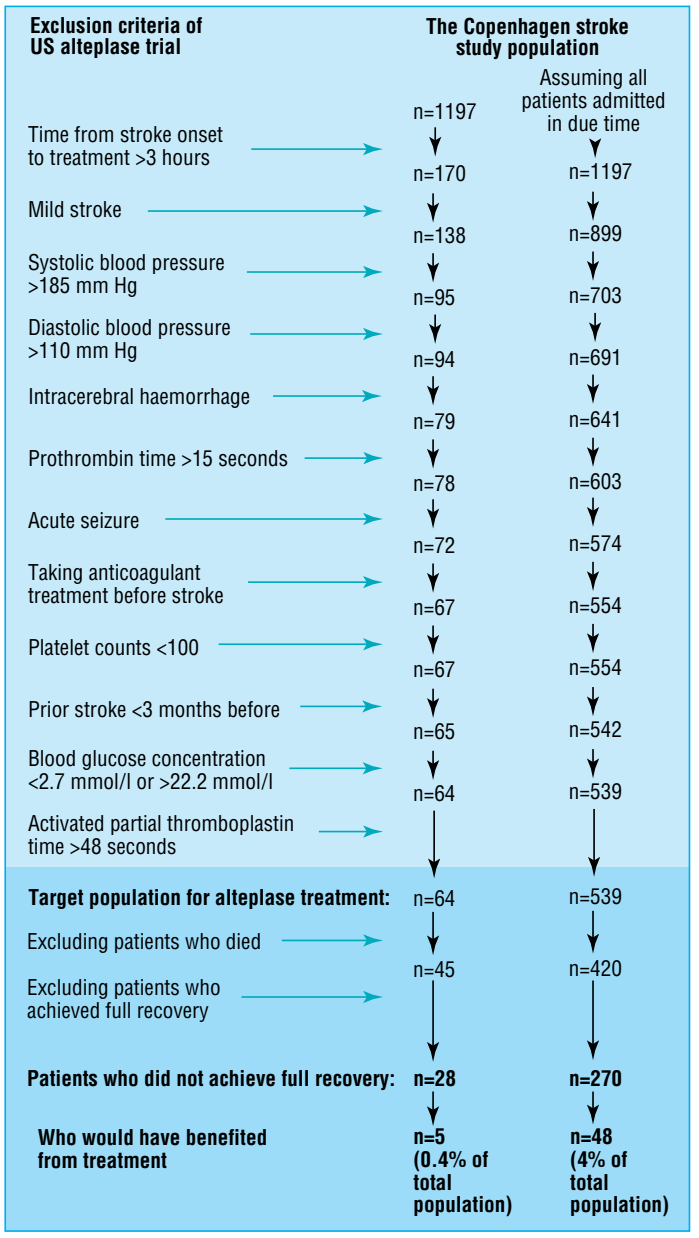

Flowchart showing impact of exclusion criteria of US alteplase trial ${ }^{1}$ on population from Copenhagen stroke study and estimate of number of patients who would have benefited from alteplase treatment

patients $(17 \times 0.32=5(95 \%$ confidence interval 1 to $12))$ or $0.4 \%(0.1 \%$ to $1.0 \%)$ of the stroke population would have benefited if alteplase had been available. 